\title{
Collective Rex Excavation and Lost Media from the Last Century of British Prehistoric Studies
}

\section{Jennifer Wexler, Andrew Bevan, Chiara Bonacchi, Adi Keinanx Schoonbaert, Daniel Pett, Neil Wilkin}

This paper will look at the 'media' used to record and store archaeological data over the last century, in particular reference to the National Bronze Age Index (NBAI) housed at the British Museum now being digitized as part of the MicroPasts Project (http://micropasts.org). Developed in 1913 as one of the first catalogues to document British and European prehistory on a large scale, this corpus took the form of an illustrated card catalogue containing around 30,000 doublex sided cards, serving as a sort of proxy for the objects they recorded. While widex scale dispersal of archaeological archives has not been generally possible, new forms of media and digital engagement perhaps now offer us some innovative inroads into some of these issues. This paper will examine how we can 'excavate' these antiquated media sources to both draw meaning and data from these overlooked archives as well as how by employing new technologies, such as the openx source crowdx sourcing platform utilized by MicroPasts (http://crowdsourced.micropasts.org), we can open up new avenues of research and public engagement to make these collections relevant to

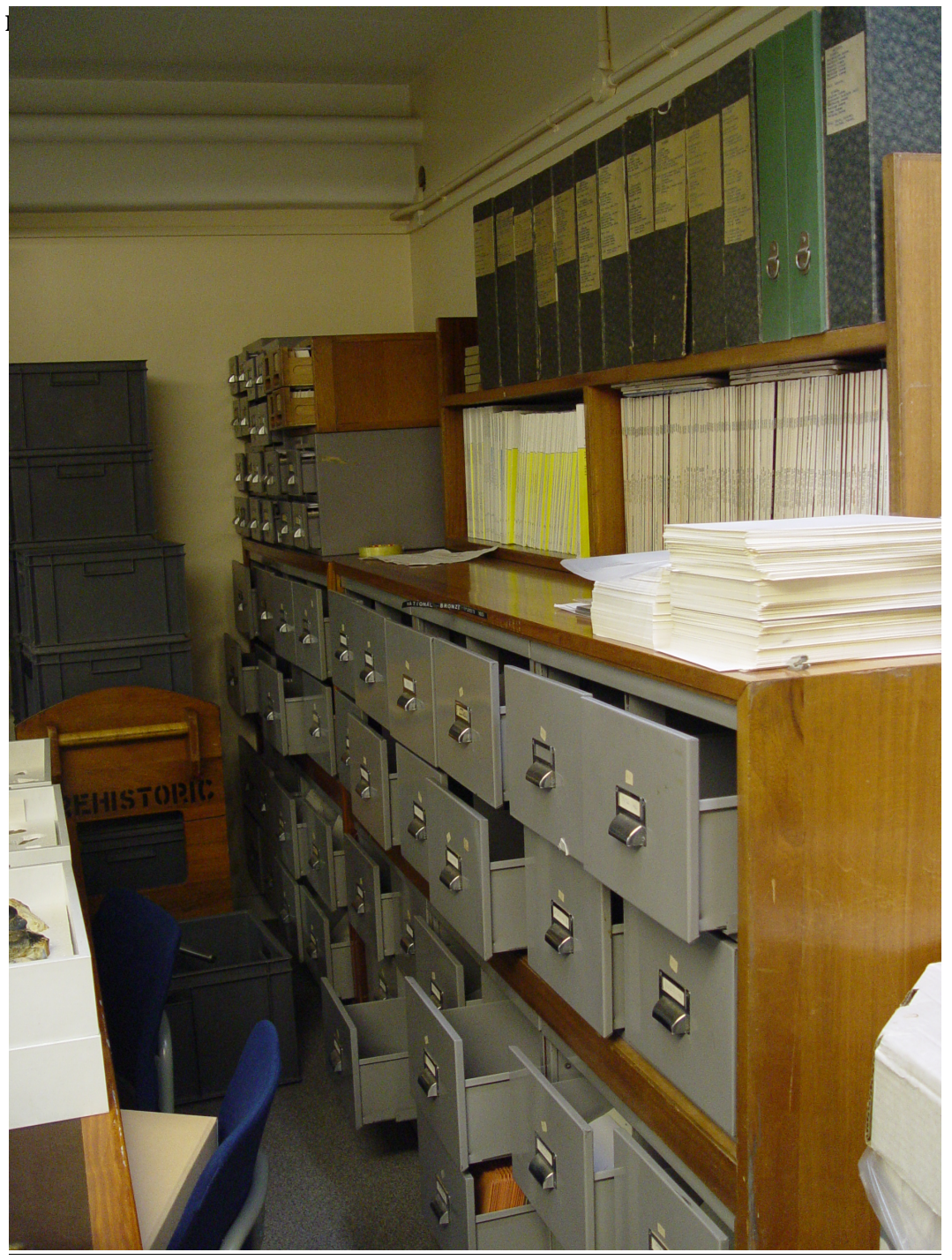

Fig. 1 - Card Index storage at the British Museum. (C) J. Wexler CC-BY 
"The archive is traumatic, testimony not to a successful encounter with the past but to a...' missed encounter with the real'"-that is, an allegory of the impossible bridging of a gap." (Ernst 2013: 114)

As we approach the 'media' used to record and store archaeological data over the last century or so, Huhtamo's (2010) definition of media archaeology as a 'historically-attuned enterprise' that involves 'excavating forgotten mediacultural phenomena' certainly seems apt to describe the types of processes involved. How do we begin to contemplate the thousands of forgotten archaeological archives hidden away in repositories (for example, see fig. 1) all over the world? These lost worlds where many scholars have toiled away for years, trying to record every detail and bit of information (fig. 2) available about rare and precious archaeological objects in an attempt to bring order and understanding to an almost incomprehensible past seems now like a most Sisyphean task.

\section{British Association Committee on Bronze Implements}

Dear Sir,

We wish to draw your attention to a line of research which we think may prove of interest to you. It has long been realised that various events that happened in the Bronze Age, such as movements of peoples and of trade, have had marked effect upon the subsequent history of Europe, and that it is by the study of these problems we may hope to solve many of the obscurities which meet us at the dawn of the Historic Age.

Experience has shown us that many of these difficulties may be cleared up by an exhaustive study of the distributions of certain types of implements and weapons used at this period. It is true that many of such objects have disappeared, while others lying in museums and private collections entirely lack evidence of the site of their discovery ; but there are quite a sufficient number of well-authenticated specimens to solve most, if not all of the problems involved.

The specimens are, however, scattered throughout a large number of museums and collections. In many cases no adequate description has been published. It has been felt that if a complete corpus could be formed, if only in manuscript, a great difficulty would be removed from the path of students of this period.

This Committee has decided, therefore, to compile such a corpus in the form of an illustrated card catalogue of all the "metal objects of the Bronze Age in the Museums and Collections in the British Isles," hoping that perhaps their example will be followed by students of the subject in other countries in Europe.

The Committee was formed at the Birmingham Meeting of the British Association in 1913, but owing to the war little progress could be made until 1919 , though about 1,000 cards were completed during that period.

Fig. 2 - Newspaper clipping from 1920 calling for public assistance in setting-up the National Bronze Age Implement Index (NBAI) by the British Association Committee.

The physical 'media' of choice was often the index card, a type of heavy paper cut to a standard size, used for recording and storing small amounts of discrete data. Invented by Carl Linnaeus, the father of modern taxonomy in the mid-1760s (Müller-Wille \& Scharf 2009), it is an Enlightenment tool for classifying the world that became ubiquitous in museums and archives by the Victorian era of extensive collecting. 


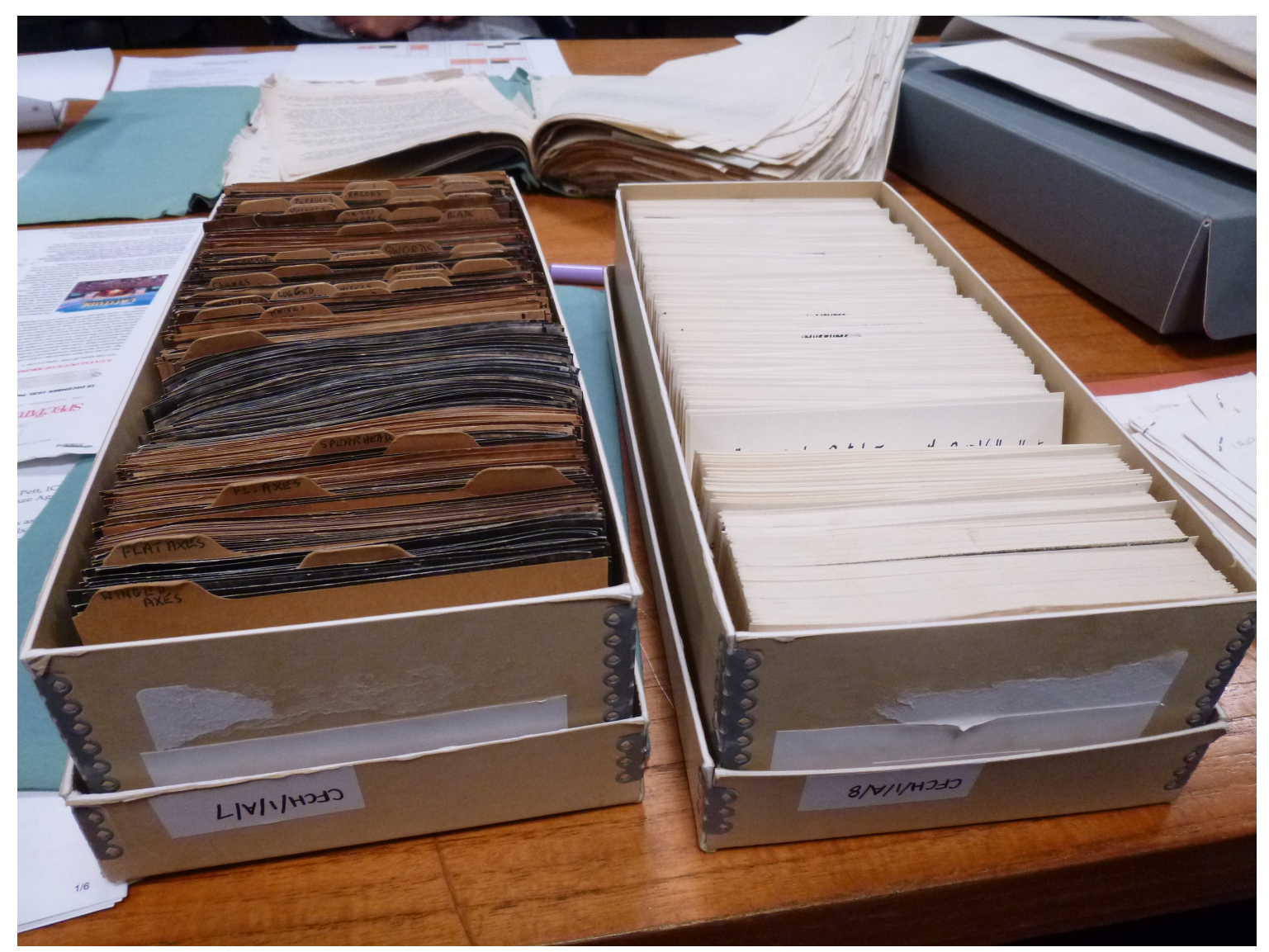

Fig. 3 - Index cards at the Institute of Archaeology Archive, University of Oxford. (C) J. Wexler CC-

BY

While stored in a fixed, conventional order (fig. 3), often alphabetically, index cards could be retrieved and shuffled around at will to update and compare information at any time. This employment of a flat surface (a map, a list, a file, a census, the wall of a gallery, a card-index, a repertory), has, as Latour has pointed out, commonly enabled one to 'master' a question or to 'dominate' a subject $(1986,19)$. The standardized index card allowed for a 'pliable combinability' of texts and objects, produced at a distance from their point of origin, which could be assembled into new networks and relationships (Bennett 2013, 39). This opened up new ways to compare and organize objects, collections, and cultures (see Harrison 2014 for further discussion). For archaeological archives, card indexes tended to be used to classify types of objects, which were then filed according to the typological and chronological information contained in the cards, certainly in the hopes of 'mastering' a time period or object type.

The cards and documents illustrated here come from the National Bronze Age Index (NBAI) stored at the British Museum (BM), developed in 1913 as one of the first catalogues to document British and European prehistory on a large scale. Known as the 'principal instrument of research in the British Bronze Age', the main concept behind the creation of the Index was the idea that by compiling a corpus of all Bronze Age metal objects found in the various museums and collections across the UK, it would be possible for the first time for researchers to study 'the movements of peoples and trade through the exhaustive study of the distributions of certain types of implements and weapons used in the period'. This corpus took the form of an illustrated card catalogue (employing $25 \times 18 \mathrm{~cm}$ Globe-Wernicke Co. standard filing cards), with each index card detailing object find spots and types, alongside detailed line drawings and a wide range of further information about the object's context of discovery, illustrated below. For 
over 80 years, it represented the highest standards of Bronze Age object studies, eventually containing around 30,000 double-sided cards, and was worked on by numerous well-known prehistorians and former BM curators, most famously Christopher Hawkes in the 1930s-1960s and Stuart Needham in the 1970s1990s.

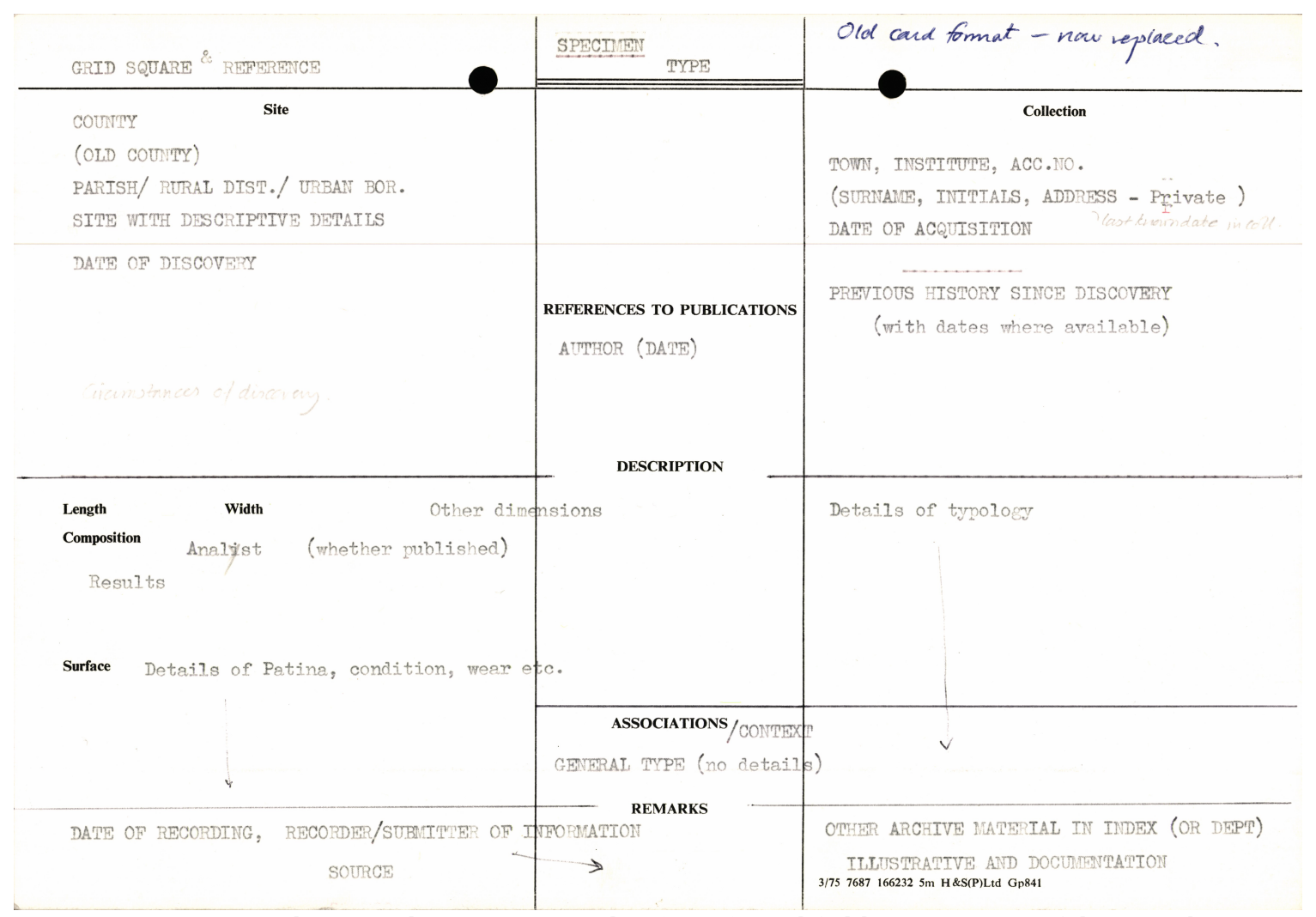

Fig. 4 - Systemized National Bronze Age Index (NBAI) card fields (C) Trustees of the British Museum CC-BY

The amount of information contained on such cards could be extensive and intriguing. Often we see a tension exhibited in these cards between systematization (fig. 4) and free-form narrative (fig. 5), beautiful typological drawings and quick sketches (fig. 6), classification and creativity. The human hand, though, is always present in what we see, bringing to mind Harris' conception of an archive as "a crucible of human experience, a battleground for meaning and significance, a babel of stories, a place and a space for complex and ever-shifting power- plays. Here one cannot keep one's hands clean" (Harris 2002, 85). 


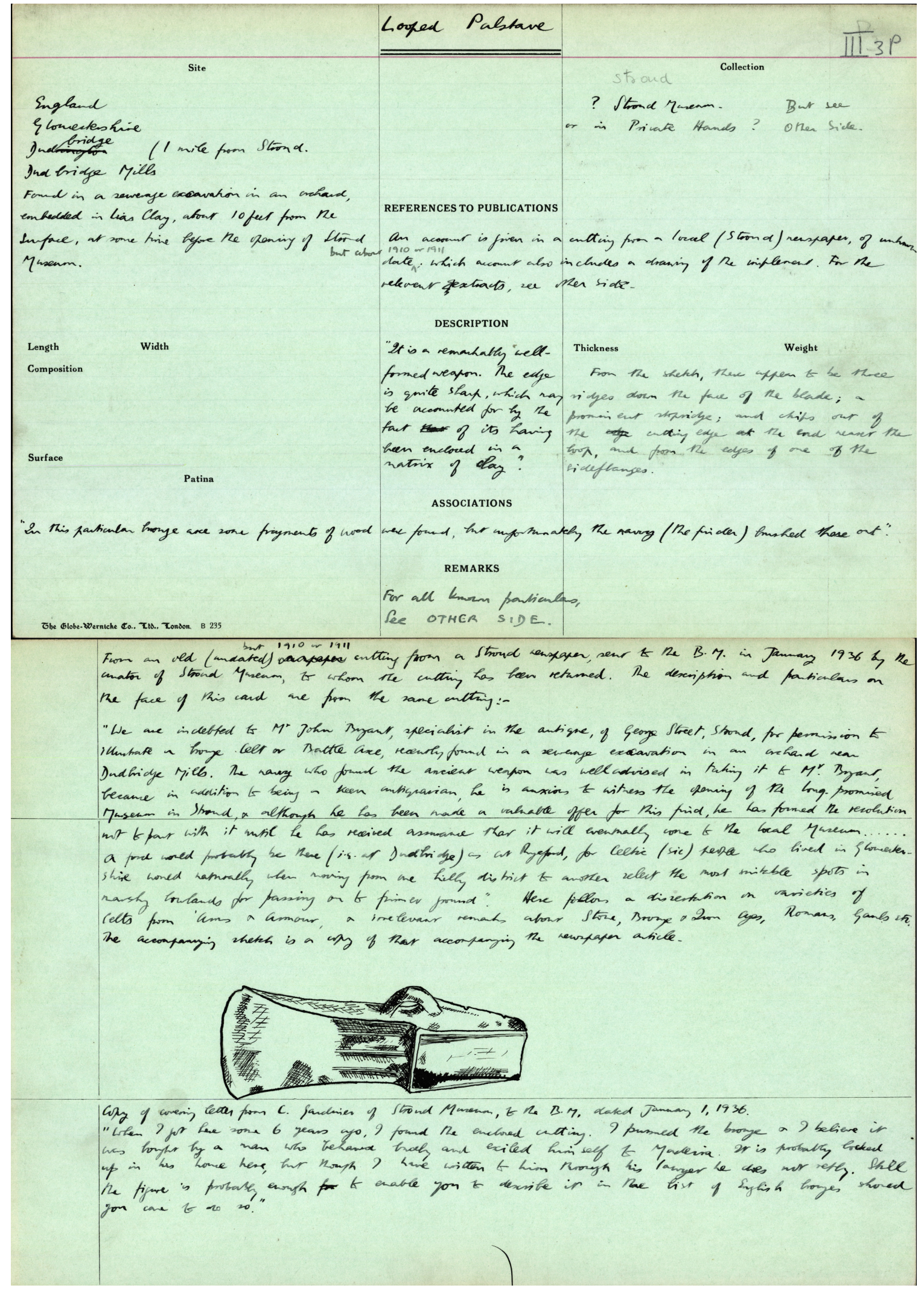

Fig. 5 - One of the index card records with extensive narrative from the National Bronze Age Index (NBAI) (C) Trustees of the British Museum CC-BY 


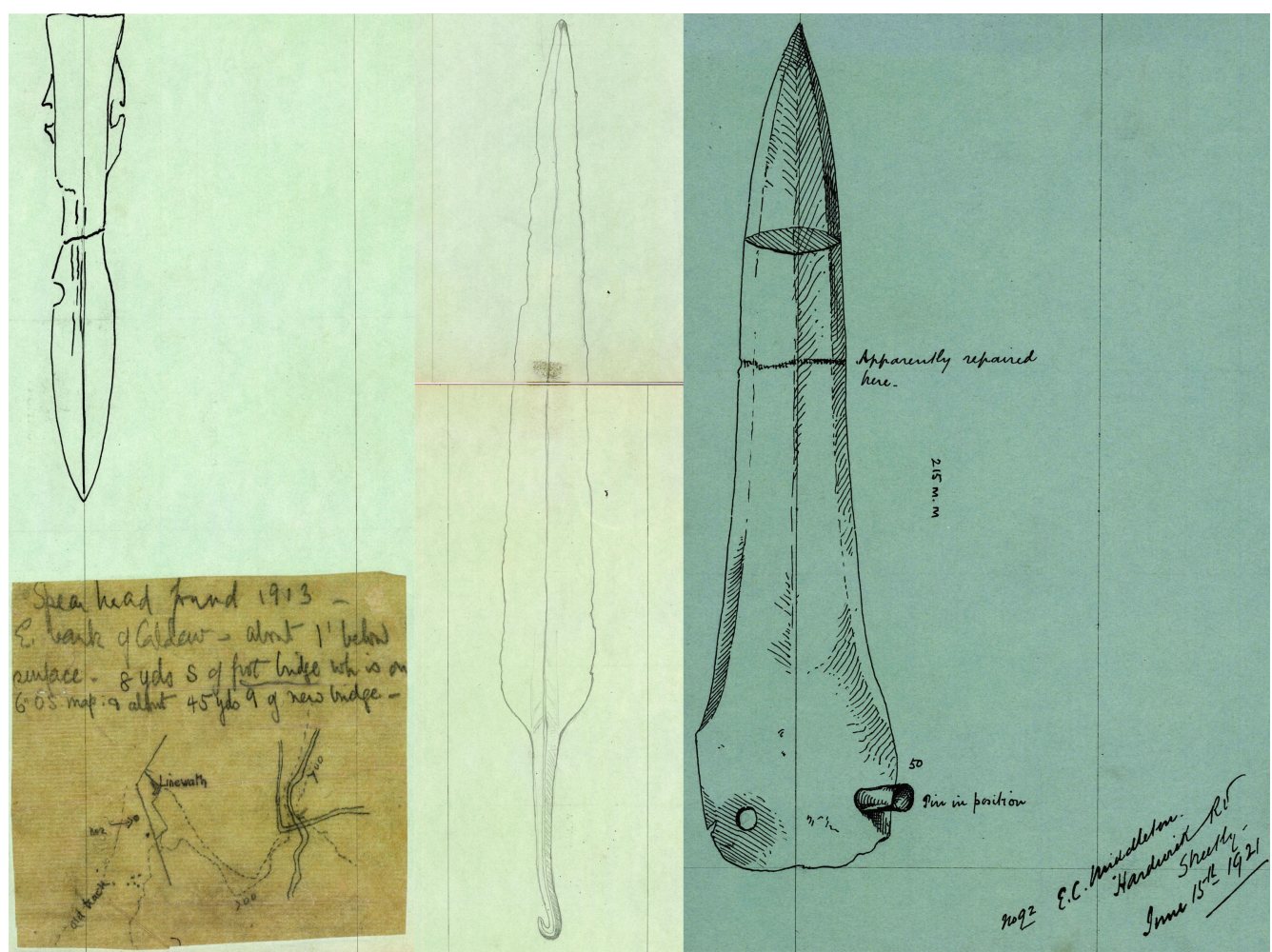

Fig. 6 - Variations in Index card illustrations from sketches to measured typographic drawings (C) Trustees of the British Museum CC-BY

Beyond recording typological data, often these cards contain additional information (fig. 7) offering fascinating insights into the circumstances of the object's discovery.

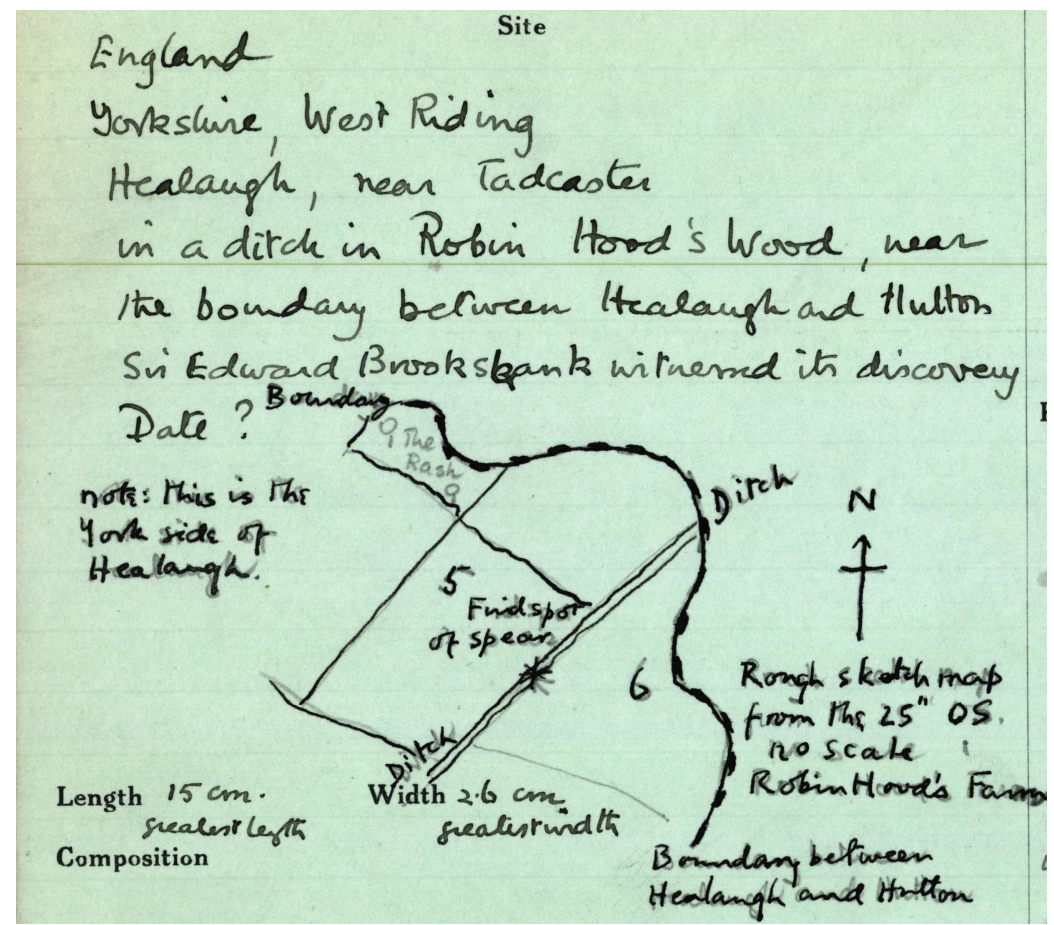

Fig. 7 - 'X' marks the spot. Detail of a NBAI card, showing the findspot of a spearhead (C) Trustees of the British Museum CC-BY

There is serendipity in the archives, as well. We have cards that record donations by Queen Victoria (fig. 8) to the BM of a bronze axe found in Windsor Great Park in 1866. Another card (fig. 9) records an object discovered in 1808 at 
Osmington Hill, Dorset whilst cutting a hill figure dedicated to King George III, who would often pass-by on his way to his seaside residence at Weymouth. In these cases, and many others, the cards' record of historical moments or connections to significant personage seems to eclipse their primary function as a record of archaeological artefacts.

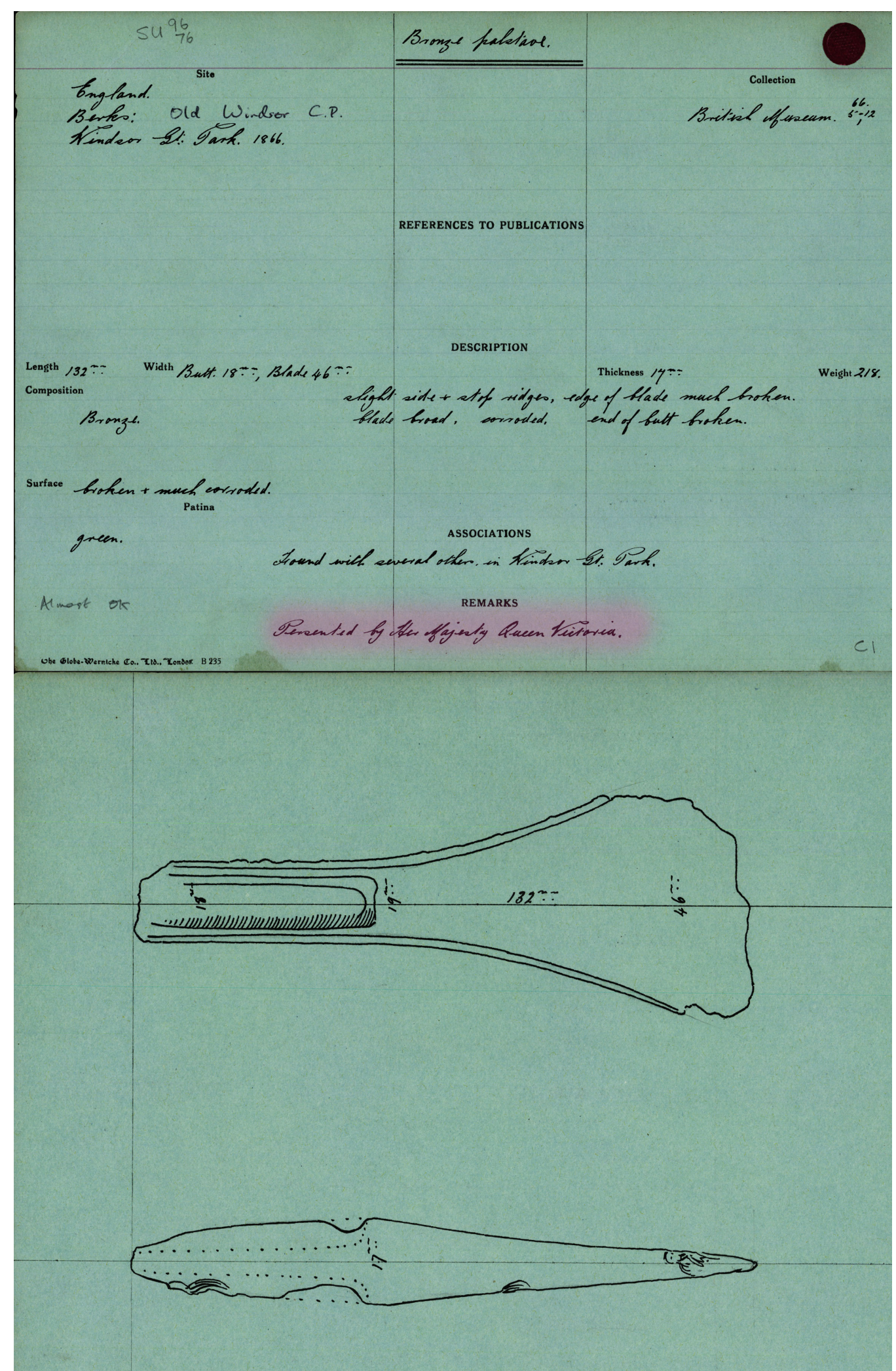

Fig. 8 - NBAI card recording the donation of a bronze palstave axe found in Windsor Park in 1866 and donated by Queen Victoria to the British Museum. (C) Trustees of the British Museum CC-BY 


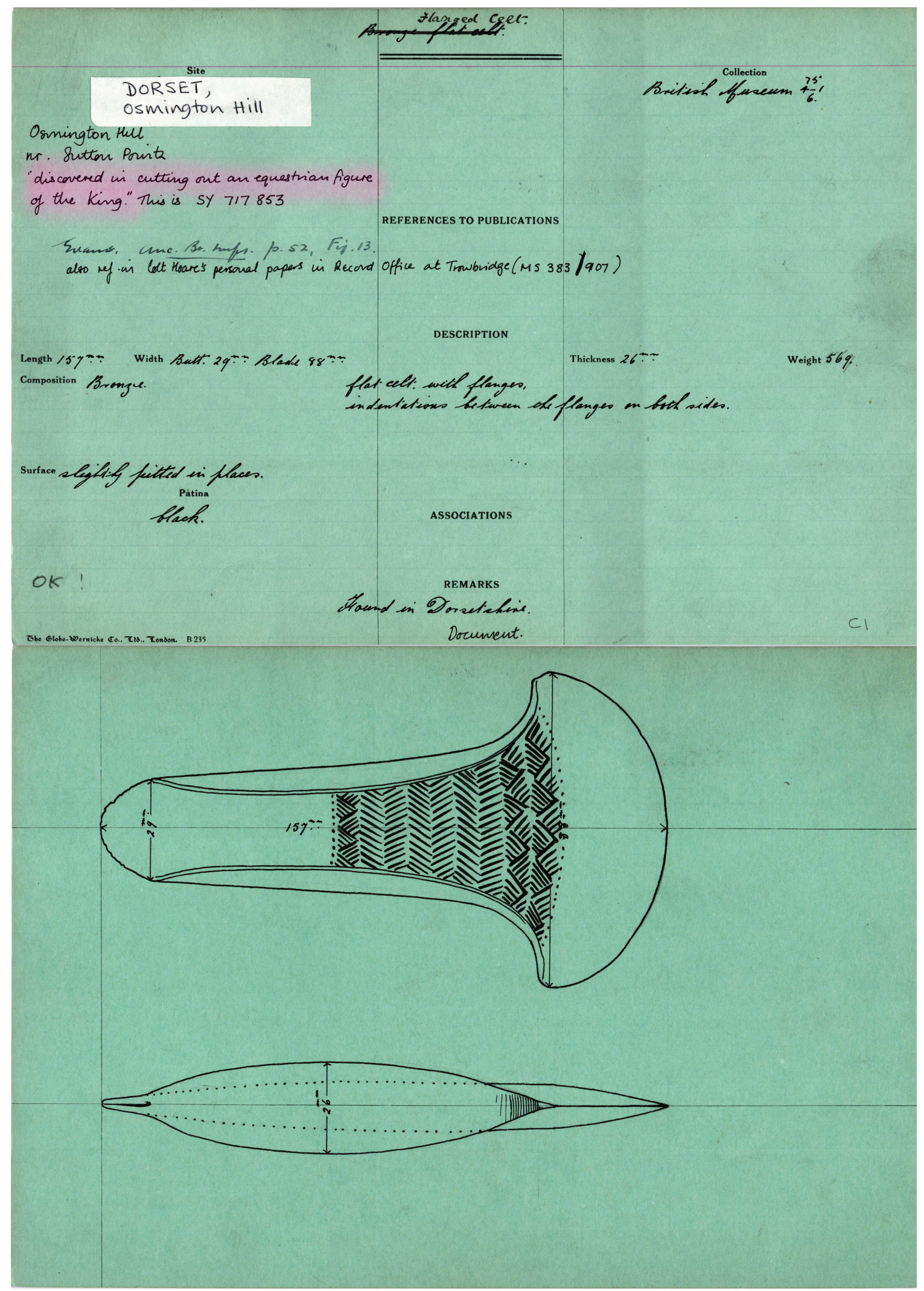

Fig. 9 - NBAI card recording a flanged axe 'discovered in cutting out an equestrian figure of the king' from Osmington Hill, Dorset. (C) Trustees of the British Museum CC-BY

These cards, in turn, begin to act as a sort of proxy for the objects themselves, an idea of materiality. The records are descriptions of something material on a medium that is a 'material' itself, but in reality it is the information itself that is the historical artefact and the main objects of study (Newman 2011, 9). Consequently, the record of the human interaction (fig. 10) with these archives, proves to be just as fascinating to study as the information actually contained in the records, as contributors to the field of 'History of Archaeology' can certainly attest to (for example, see Murray 2014). 


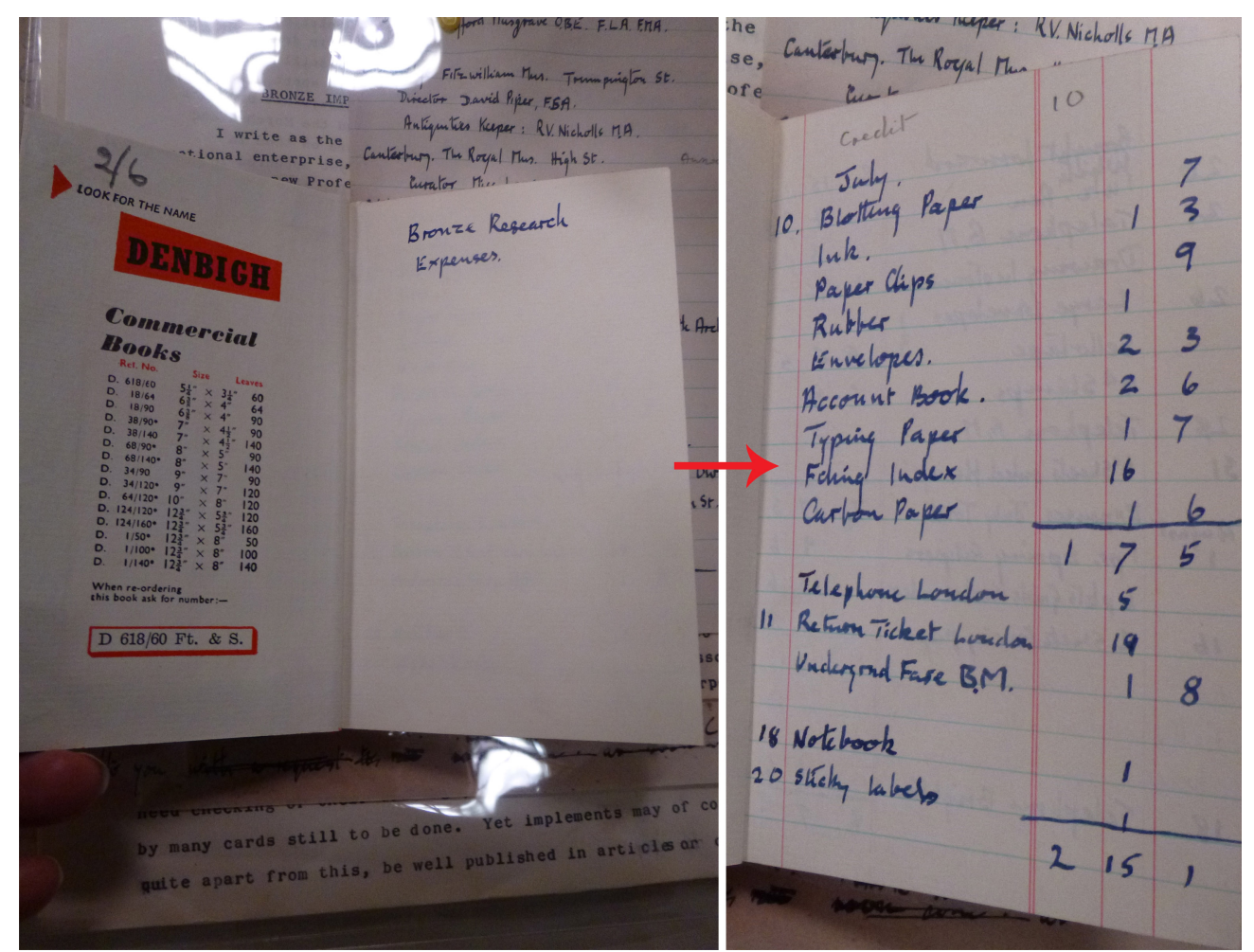

Fig. 10 - Hawkes' book recording 'Bronze Research Expenses' in connection to his work on the Index at the Institute of Archaeology's Archive, University of Oxford. (C) J. Wexler CC-BY

Along with the connected archival material, the cards exhibit the curatorial practices at the time of recording. Many have been altered numerous times as classification schemes and recording procedures have changed over time, documenting not only the basic archaeological information but also the history of shifting archaeological practices. 


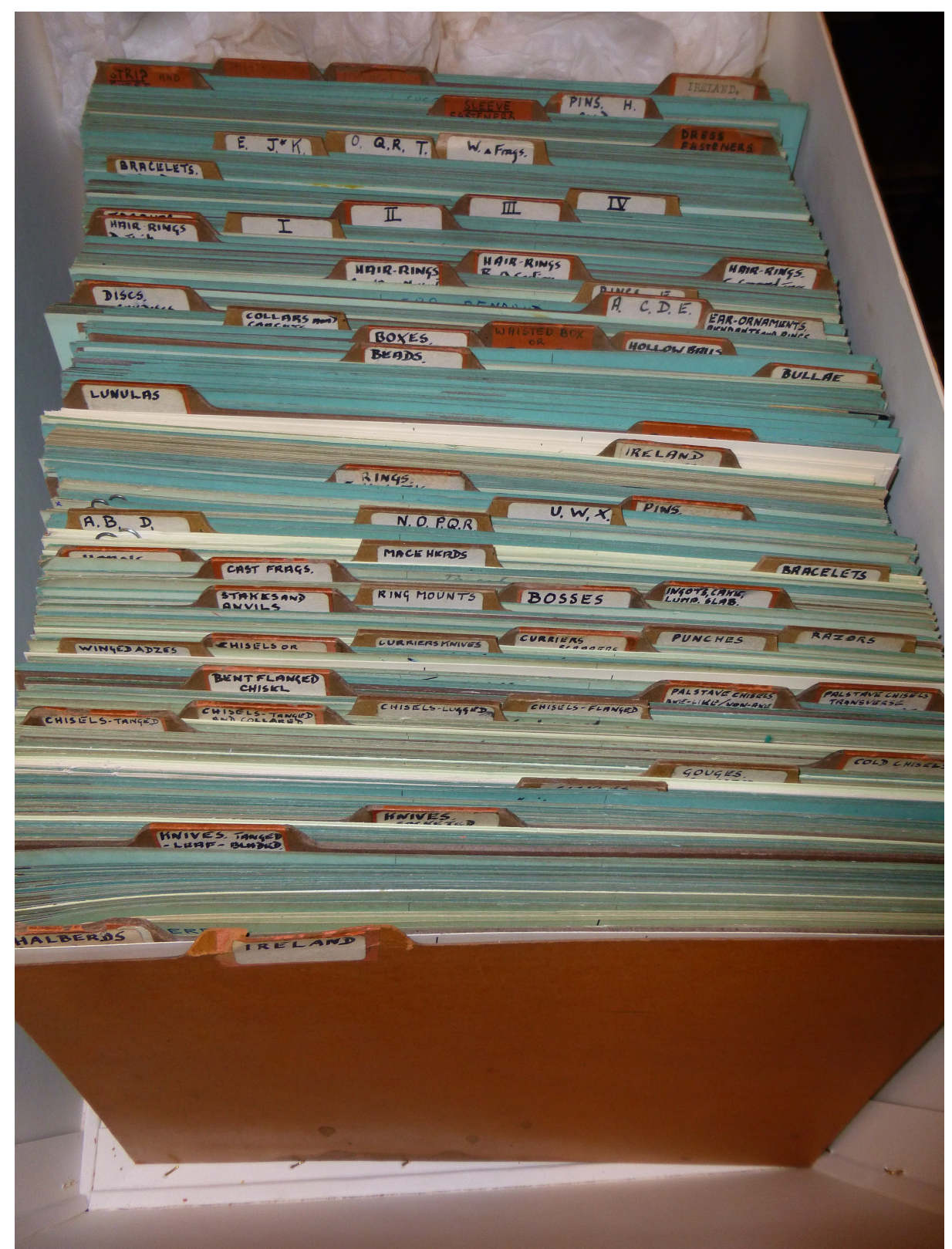

Fig. 11 - A box of Index cards exhibiting Hawkes' schematic re-organization of the Index from 1954-1965. (C) J. Wexler CC-BY

The Index varied between being a public reference collection to being a tool for private research largely depending on the whims of the person and institutions in charge of it. This is most obviously played out from 1955-1965, when the Index was loaned from the BM, where it was publically accessible, to the Institute of Archaeology, Oxford University under the supervision of Prof. Christopher Hawkes, the new Chair of European Archaeology. The reasoning behind this move was that he had been in charge of the Index when he was an Assistant Keeper in the Department of British and Medieval Antiquities at the BM and he was 'wishing to supervise its re-classifying, indexing, and augmentation'. While Hawkes did greatly enhance the Index, it very much became his personal research collection, kept away from both the public and other scholars, which he used to pursue his theories of Bronze Age metalwork chronologies (see Bradley 2013 for further discussion). This is most visibly seen (fig.11) in his reorganization of the entire Index according to his (unpublished) typological scheme, the particulars (fig. 12) of which have only recently been rediscovered and catalogued at the Institute of Archaeology's archive. The Index became a public reference collection once again after being returned to the BM in 1966, 
although it was not actively researched again until 1973 when Stuart Needham took over its stewardship, and was largely abandoned by the 1990s.

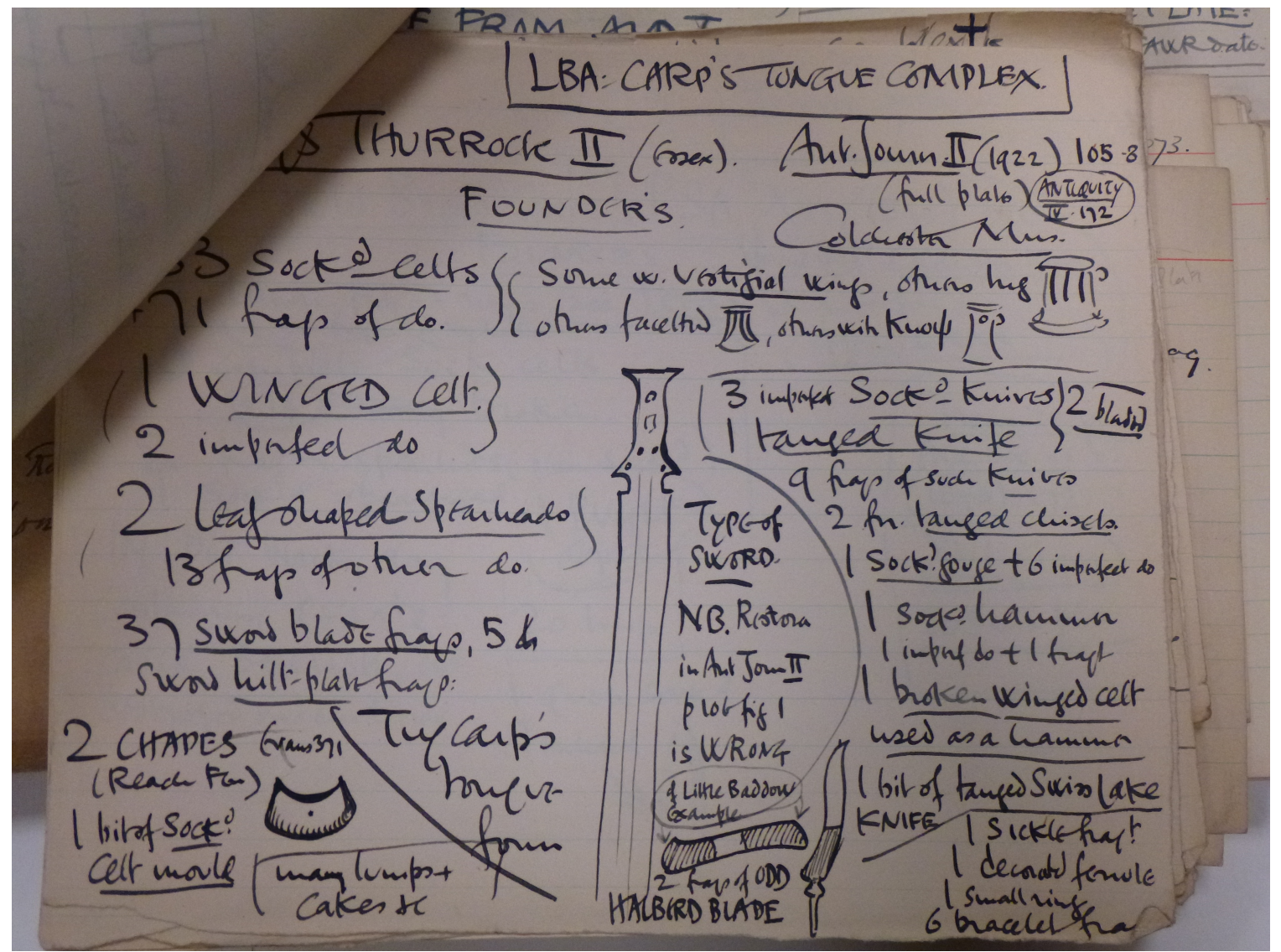

Fig. 12 - Hawkes' reworking of Late Bronze Age sword types, Institute of Archaeology's Archive, University of Oxford. (C) J. Wexler CC-BY

\section{Switching 'Media' from Old to New}

The multi-layered history of card indexes in archaeological studies is equally intriguing to study and complicated to deal with. How can we approach or, indeed, 'excavate' these antiquated media sources to both draw meaning and data from these overlooked archives as well as make them relevant to modern communities?

Index cards continue to act as 'mobilization devices', allowing access to information and data about a physical object without actual interaction with this object in the physical world (Latour 1986,10). However, although indexes are a good example of a type of mustering technology in which dispersed items of knowledge are codified and brought into the centre for agonistic (e.g. academic, imperial, economic, nationalist) arguments, in reality the politics of aggregation and dispersal often makes these indexes largely inaccessible. The popular notion that archives are, as Parikka (2013) states, "remote, largely obsolete institutions... antiquated, inevitably dusty libraries" often hidden away from the public is not completely false unfortunately. In the case of the NBAI, for example, although it has been moved around over the last hundred years, as mentioned previously, it has remained for much of its existence in a largely inaccessible, offsite BM storage facility where its visitor's book records only six visitors over the course of 30 years (though conspicuously this does include everyone who has ever written significant books on Bronze Age metalwork during that period). Even if this Index and others were more accessible, specialist knowledge would still be needed to even begin to approach such large behemoths of information. 
Wide-scale dispersal, therefore, has not been generally possible but new forms of media and digital engagement perhaps now offer us innovative inroads into some of these issues (for example, see Bonacchi 2012, Richardson 2013).

As part of the MicroPasts Project (http://micropasts.org), the digitization of the entire Bronze Age Index has been undertaken. This project is focused on demonstrating how the interplay between reassessing archaeological archives and the employment of new technologies can open up new avenues of research and public engagement. The MicroPasts project employs an open source crowdsourcing platform (http://crowdsourced.micropasts.org as shown in the screenshot in fig. 13) in order to solicit help from members of the public, also known as 'citizen scientists' or 'citizen archaeologists', to assist us with transcribing these cards (Bevan et al. 2014, Bonacchi et al. 2014a, Bonacchi et al. 2014b, Keinan-Schoonbaert 2014, Doherty 2014).

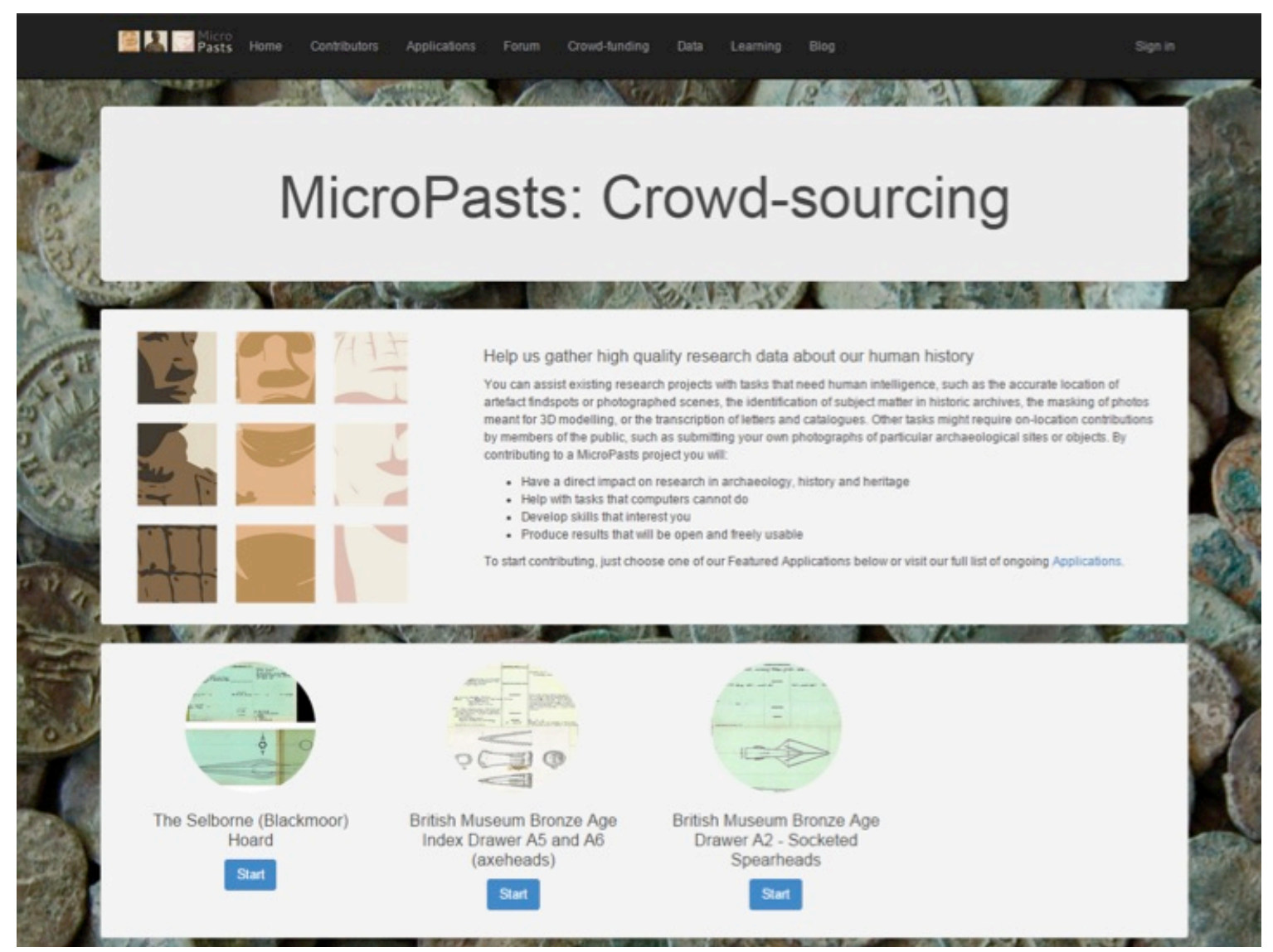

Fig. 13 - Crowd-sourcing platform for MicroPasts (http://micropasts.org), each new 'app' represents one 'drawer' of index cards.

Reflecting the existing physical organization of the Index, pictured in fig. 1, each 'app' generally represents one 'drawer' (e.g. Drawer A9 - Palstaves) organized by object type and geographical location, and each individual card in the drawer is scanned at a high resolution, available via our Flickr site (http://flickr.com/photos/micropasts) and stored in three secure locations for backup integrity. For each transcription app, the MicroPasts collaborators are prompted to fill-in a structured field interface (fig. 14) based on the contents of the cards, and the completed transcribed data is available for download from the project's website under an open license. These data will eventually be incorporated into the Portable Antiquities Scheme's database (https://finds.org.uk), which on its own includes over one million objects (of which over 15,000 are attributed to the Bronze Age) discovered by the public in England and Wales, eventually making the NBAI records not only easily 
accessible to the public but also creating possibly the largest national database of prehistoric metal finds anywhere in the world.

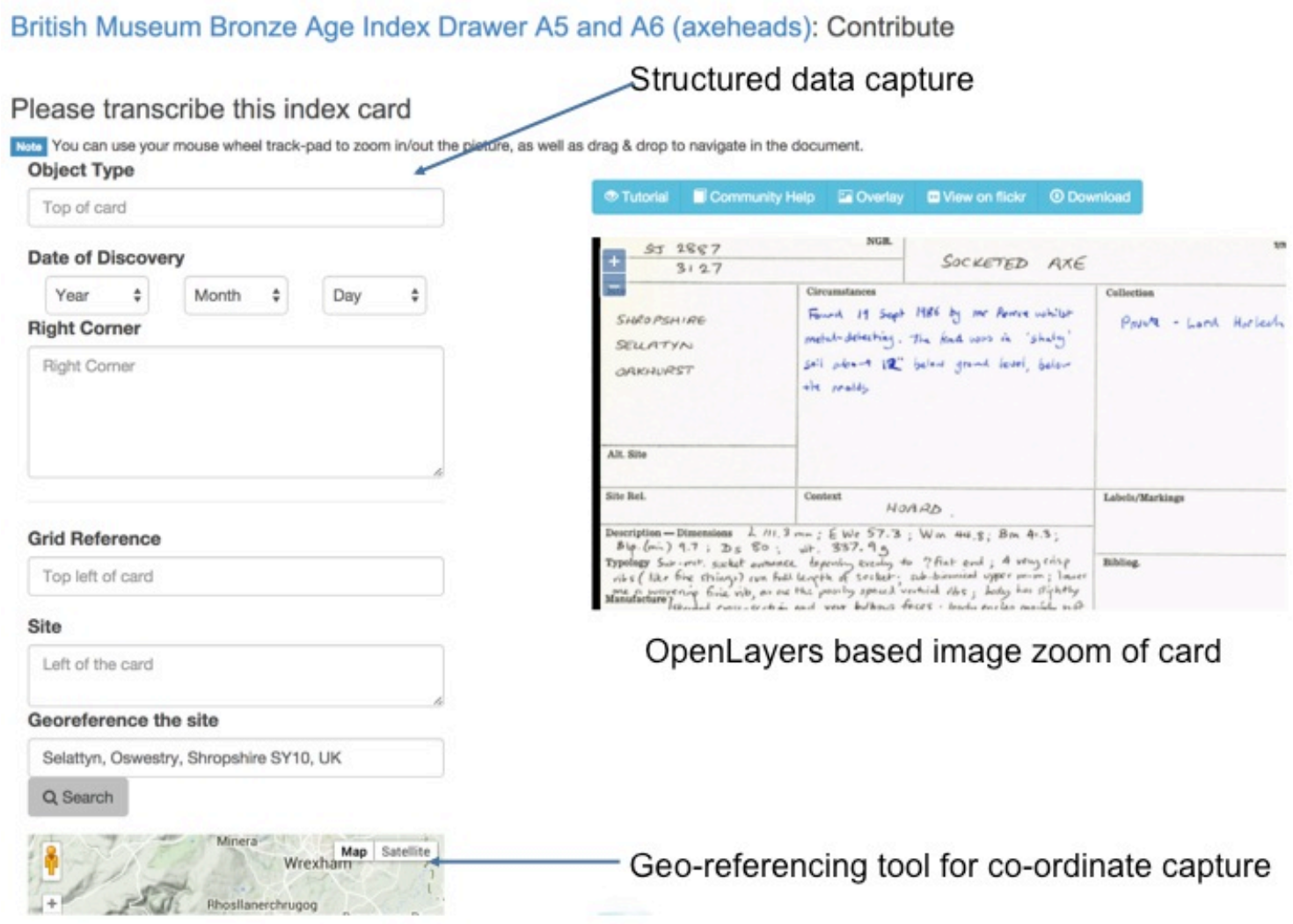

Fig. 14 -MicroPasts' interface for transcribing data from the digitized Index card.

In a way, we are attempting to fulfill the original intentions of the creators of the NBAI from the early 20th century (fig. 2), by once again calling on the public's help with documenting and transcribing the archive as well as making the Index a fully renewed publicly-accessible resource. Crowd-sourcing, therefore, can be seen as an act of knowledge aggregation by the dispersed-many rather than the aggregated-few. These processes can be connected to the concept of the 'collaborative museum', where the museum can be viewed as a series of 'anthropological assemblages mobilized through existing and emerging scientific-administrative and public-civic apparatuses' creating new social actions and networks (Harrison 2014, 231; Bennet 2013). By changing the medium of the Index via digital technologies, we are removing the institutional controls, for better or worse, and distributing the agency of this data.

Why are people so intrigued to help with this project? While this is something we will be looking at more closely in the future, perhaps it is because it removes the 'remoteness' of the archives both symbolically and physically. By digitizing records formerly only accessible to few experts and museum staff, they are suddenly becoming democratized, open-access resources for anyone to engage with, albeit with the existing but, arguably, progressively shrinking limits of a digital divide. It took a new infrastructure of communicating realities-the impact of digital media-to put this critique of historical discourse into mediaarchaeological terms and practice. In an age of renewed archival fever, the reaggregation and digital mustering of old archives, along with the virtual reaggregation of object collections via 3D proxies (fig. 15), is also a very popular act. Co-production of archaeological data not only removes the traditional idea of 'authority' (Richardson 2013), opening up the possibilities for multi-vocal 
engagement with the archival record, it gives people a sense of what archaeologists and archivists actually do and the means to actively help them with their work. On the MicroPasts forum, one of the users, for example stated:

Part of the appeal (of the transcriptions) for me is seeing how the original authors put a little bit of themselves into their record cards, and obviously took pride in analyzing and recording the artefacts. I'm just completing a card now in which the patina is described as 'Beautiful apple green'. (http://community.micropasts.org/t/just-a-silly-thought/140/5).

This engagement and ongoing dialogue about the Index also creates new archival records of human interaction via social media (Twitter, Facebook), adding to our archival layer cake.

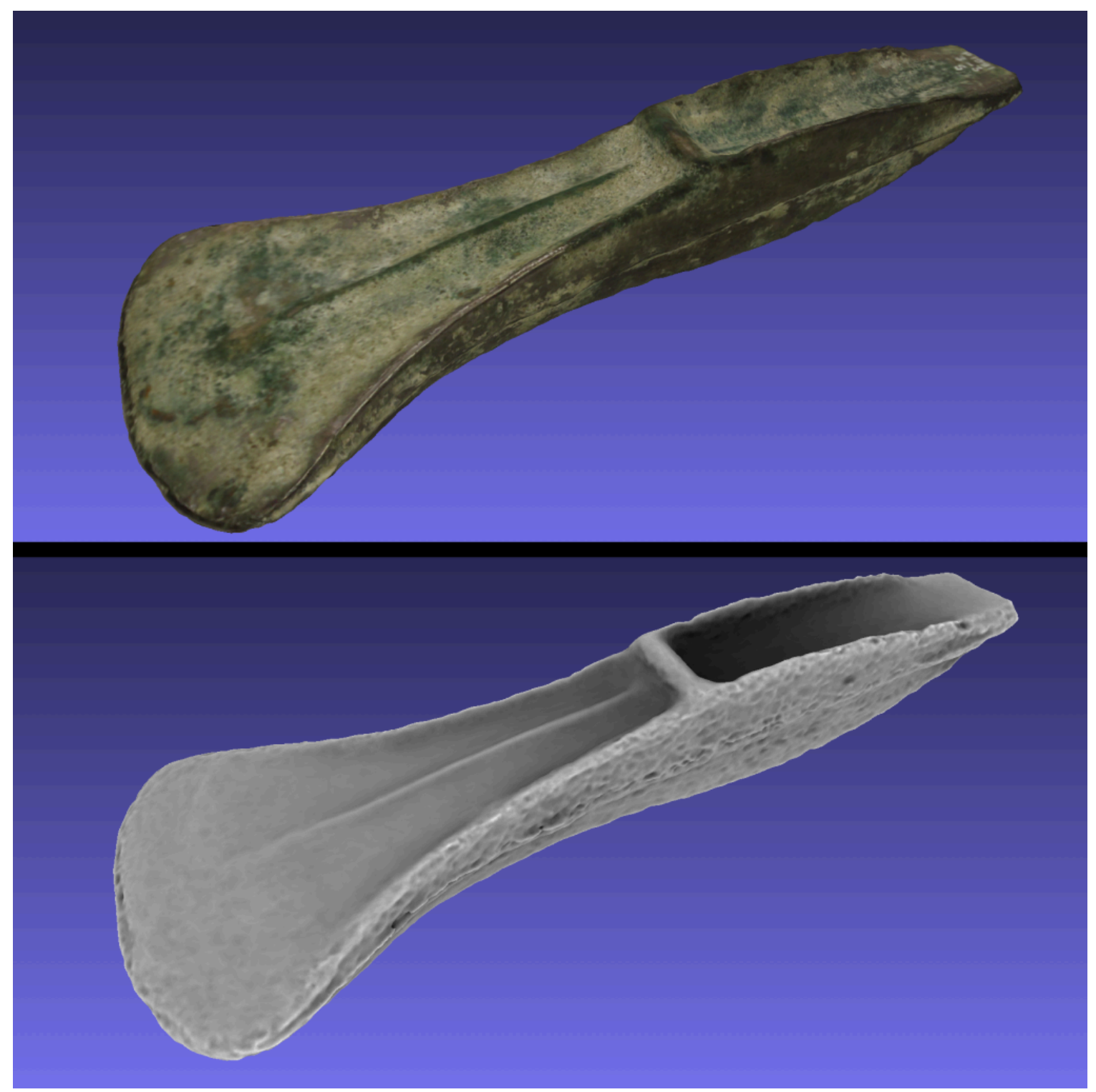

Fig. 15 - A 3D model of a Bronze Age palstave shown in the MicroPasts WebGL 3D viewer.

While this switch in media from a physical, paper format to a digital database for archiving archaeological data not only makes this information increasingly Cartesian, e.g. mathematical objects recorded using binary code, the forms in which data are stored and in which they are presented become distinct entities unlike its paper antecedent (Ernst 2013, 83, 93, 115). Now the image on the screen is just a digital representation or surrogate of the data encoded within, useful as a tool for further research and data processing but far removed from its 
original format. With growing digital accessibility comes the increasing responsibility to preserve and update these digital archives as well as the paper ones they represent, especially if we view the digital record as a modern piece of material culture (Newman 2011, 9). Ultimately one media does not completely replace the other, but greater utilization of digital media simply changes and extends the terms of engagement, accessibility, and the flow of information from antiquated archaeological archives to the community and back again.

\section{$\underline{\text { References }}$}

Bennett, T, 2013. "The 'Shuffle of Things' and the Distribution of Agency". In Reassembling the Collection: Ethnographic Museums and Indigenous Agency, edited by R. Harrison, S. Byrne, and A. Clarke, 39-60. Santa Fe: School for Advanced Research Press.

Bevan, A., Pett, D., Bonacchi, C., Keinan-Schoonbaert, A., Lombraña González, D., Sparks, R., Wexler, J., and Wilkin, N., 2014. "Citizen archaeologists. Online collaborative research about the human past". Human Computation 1(2) 183197.

Bonacchi, C. (ed.), 2012. Archaeology and Digital Communication. Towards Strategies of Public Engagement. London: Archetype Publications.

Bonacchi, C., Bevan, A., Pett, D., Keinan-Schoonbaert, A., Sparks, R., Wexler, J. and Wilkin, N., 2014a. "Crowd-sourced Archaeological Research: The MicroPasts Project”. Archaeology International 17, 61-68.

Bonacchi, C., Bevan, A., Pett, D., Keinan-Schoonbaert, 2014b. "Crowd- and Community-fuelled Archaeology. Early Results from the MicroPasts project". Proceedings of the 42nd Annual Conference on Computer Applications and Quantitative Methods in Archaeology, CAA 2014, edited by L. Costa, F. Djindjian, F. Giligny, P. Moscati, 1-10. Amsterdam : Amsterdam University Press.

Bradley, R., 2013. "Time Traveller: Montelius and the British Bronze Age after 100 Years". In Counterpoint: Essays in Archaeology and Heritage Studies in Honour of Professor Kristian Kristiansen, edited by S. Bergerbrant and S. Sabatini, 649-653. Oxford: BAR International Series 2508.

Doherty, J., 2014. “Crowdsourcing the Bronze Age” Available at: http://pybossa.com/blog/2014/06/05/crowdsourcing-the-bronze-age/ (accessed 26.2.2015)

Ernst, W., 2013. Digital Memory and the Archive. Minneapolis: University of Minnesota Press.

Harris, V., 2002."The Archival Sliver: Power, Memory, and Archives in South Africa". Archival Science 2, 63-86.

Harrison, R., 2014. “Observing, Collecting and Governing 'Ourselves' and 'Others': Mass-Observation's Fieldwork Agencements”. History and Anthropology 25, 227 245.

Huhtamo, E., 2010. "Natural Magic: A Cultural history of Moving Images". In The Routledge Companion to Film History, edited by W. Guynn., 3-15. London:

Routledge. 
Keinan-Schoonbaert, A., 2014."MicroPasts - An Innovative Place for Progressing Research”. British Archaeology 139, 50-55.

Latour, B.,1986. "Visualisation and Cognition: Drawing Things Together". In Knowledge and Society Studies in the Sociology of Culture Past and Present, edited by H. Kuklick., 1-40. Bingley: Jai Press (Vol. 6).

Müller-Wille, S. \& Scharf S., 2009. “Indexing Nature: Carl Linnaeus (1707-1778) and his Fact-Gathering Strategies". Working Papers on The Nature of Evidence: How Well Do 'Facts' Travel? No. 36/08. London: Department of Economic History, London School of Economics.

http://www.lse.ac.uk/economicHistory/pdf/FACTSPDF/3909MuellerWilleSchar f.pdf

Murray, T., 2014. From Antiquarian to Archaeologist: The History and Philosophy of Archaeology. Barnsley: Pen \& Sword Archaeology.

Newman, M., 2011. “The Database as Material Culture”. Internet Archaeology 29, http://dx.doi.org/10.11141/ia.29.8.

Parikka, J., 2013. “Archival Media Theory: An Introduction to Wolfgang Ernst's Media Archaeology". In Digital Memory and the Archive, by Ernst, W, 1-22. Minneapolis: University of Minnesota Press.

Richardson, L., 2013. “A Digital Public Archaeology?”. Papers from the Institute of Archaeology 23, 1-12. http://dx.doi.org/10.5334/pia.431 